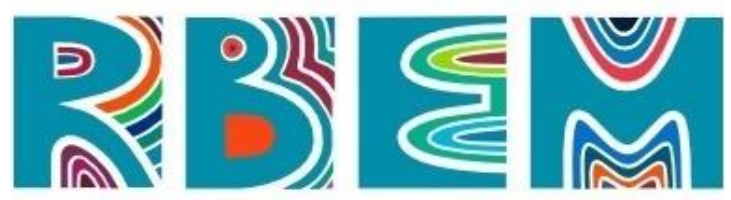

REVISTA BAIANA dE EDUCAÇÃo MATEMÁtica

\begin{abstract}
ARTIGO
dol https://doi.org/10.47207/rbem.v2i01.11996
\end{abstract}

\title{
Produções de conhecimento a partir do estágio de forma remota no Ensino Médio em Minas Gerais
}

\author{
JULIO, Rejane Siqueira \\ Universidade Federal de Alfenas (UNIFAL-MG). Doutora em Educação pela Universidade Estadual de \\ Campinas (UNICAMP). ORCID: https://orcid.org/0000-0002-3248-800X. E-mail: rejane.julio@unifal- \\ mg.edu.br.
}

\section{LIMA, Daniela Cristina}

Escola Estadual Judith Vinna e Escola Estadual Dr. Emílio da Silveira. Especialização em Matemática e Estatística pela Universidade Federal de Lavras (UFLA). ORCID: https://orcid.org/0000-0001-6036-3717. Email: daniela.cristina.lima@educacao.mg.gov.br.

Resumo: Os estágios supervisionados são centrais na formação inicial de professores de Matemática, mas pouco pesquisados. O objetivo deste artigo é analisar situações de estágio, que faz parte de uma disciplina do curso de Matemática-Licenciatura, no formato remoto, em uma escola pública de Minas Gerais. Para tanto, foi adotada a postura de professoras pesquisadoras, pelo estudo intencional e metódico, e demarcada uma visão de estágio. Os dados analisados foram as discussões de observações de aulas de Matemática do programa Se Liga na Educação, que compõe o Regime de Estudos não presencial do Estado de Minas Gerais, e a interação, por meio de entrevista semiestruturada, com a professora supervisora de estágio que atua nesta escola, no Ensino Médio. Essas análises foram realizadas com base no Modelo dos Campos Semânticos, que pode contribuir para novas pesquisas com a temática estágio. A partir disso, foi possível apontar que houve diferentes produções de significados para as observações das aulas e da entrevista, reafirmando o estatuto epistemológico do estágio, ainda que realizado de forma remota.

Palavras-chave: Estágio Supervisionado. Ensino Remoto. Modelo dos Campos Semânticos. Formação de Professores de Matemática.

\section{Knowledge Production from remotely supervised internship on high school in Minas Gerais}

\begin{abstract}
The supervised internship are centrals in initial Mathematics teacher training, but there are not a lot of research about these. The aim of this paper is to analyse internship situations, which is part of a course of Mathematics Licentiate degree, in remote format, in a public school in Minas Gerais. For this purpose, we adopted the position of researcher teachers, by methodic and intentional study and assumed an internship view. The data analysed were the discussions of observations of Mathematics classes of the program Se Liga na Educação, which are part of the State of Minas Gerais' Non-presential Study Regime, and the interaction, through semi-structured interviews, with the internship supervisor teacher who works at this high school. These analyses were carried out based on the Model of Semantic Fields, which can contribute for news research about internship. From analyses, it was possible to point out that there were different productions of meanings for the observations of the classes and for the interview, reaffirming the epistemological status of the
\end{abstract}




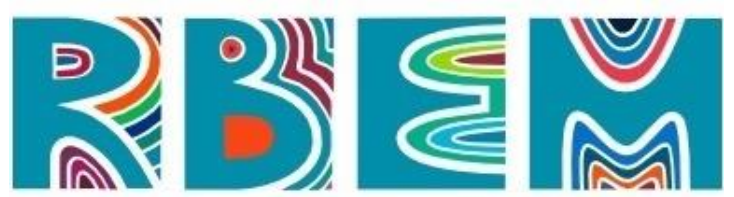

REVISTA BAIANA DE EDUCAÇÃO MATEMÁTICA

internship, even if performed remotely.

Keywords: Supervised internship. Remote teaching. Model of Semantic Fields. Mathematics Teacher Training.

\section{Producciones de conocimiento de la pasantía de forma remota en la escuela secundaria en Minas Gerais}

Resumen: Las pasantías supervisadas son fundamentales para la formación inicial de los profesores de matemáticas, pero poco investigadas. El objetivo de este artículo es analizar situaciones de pasantía, que forman parte de una disciplina del curso Matemáticas-Licenciatura, en formato remoto, en un colegio público de Minas Gerais. Para ello, se adoptó la postura de profesores investigadores, a través del estudio intencional y metódico, y se delimitó una visión de pasantía. Los datos analizados fueron las discusiones de las observaciones de las clases de Matemáticas en el programa Se Liga na Educação, que conforma el Régimen de Estudios No Presenciales del Estado de Minas Gerais, y la interacción, a través de entrevistas semiestructuradas, con el docente supervisor de pasantías que trabaja en esta escuela, en la escuela secundaria. Estos análisis se realizaron con base en el Modelo de los Campos Semánticos, que puede contribuir a una mayor investigación con el tema de las pasantías. A partir de esto, se pudo señalar que hubo diferentes producciones de significados para las observaciones de las clases y la entrevista, reafirmando el estatus epistemológico de la pasantía, aunque se realizara de forma remota.

Palabras-Clave: Pasantía. Enseñanza de forma remota. Modelo de los Campos Semánticos. Formación de profesores de matemáticas.

\section{Introdução}

Em março de 2020 vivenciamos no Brasil a interrupção das atividades educacionais presenciais por causa da pandemia decorrente do vírus SARS-Cov-2 (Covid-19), através da portaria do Ministério da Educação (MEC) no $\mathrm{n}^{\mathrm{o}}$ 343, de 17 de março de 20201. Na Universidade Federal de Alfenas (UNIFAL-MG)foram instituídas, ainda no mês de março, diretrizes para o trabalho remoto em caráter temporário (portaria $n^{\circ} 496$, de 17 de março de 2020, da Reitoria da UNIFAL-MG ${ }^{2}$ ), em 08 de Abril de 2020 ocorreu a suspensão do calendário acadêmico ${ }^{3}$, em 22 de junho do mesmo ano foi aprovado o cronograma de oferta opcional de componentes curriculares dos Projetos Pedagógicos dos Cursos de Graduação,

\footnotetext{
${ }^{1}$ Disponível em: https://www.in.gov.br/en/web/dou/-/portaria-n-343-de-17-de-marco-de-2020-248564376. Acesso em 02 jun. 2021.

${ }^{2}$ Disponível em: https://www.unifal-mg.edu.br/portal/wp-content/uploads/sites/52/2020/03/PORTARIAN\%C2\%BA-496-DE-17-DE-MAR\%C3\%87O-DE-2020.pdf. Acesso em 02 jun. 2021.

${ }^{3}$ Disponível em: https://www.unifal-mg.edu.br/portal/wpcontent/uploads/sites/52/2020/04/Resolu\%C3\%A7\%C3\%A3o-n\%C2\%BA-02.pdf. Acesso em 02 jun. 2021.
} 


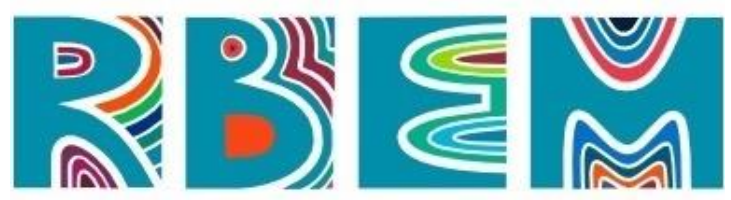

REVISTA BAIANA DE EDUCAÇÃO MATEMÁTICA

por meio de Ensino Remoto Emergencial (ERE) ${ }^{4}$ e no dia 03 de agosto de 2020 houve o retorno das atividades de graduação por meio do ERE.

Com esse retorno em caráter emergencial, uma questão colocada foi sobre a realização dos estágios supervisionados (que passaremos a mencionar somente como estágio), pois a portaria do MEC $\mathrm{n}^{\circ} .343$, de 17 de março de 2020, em seu parágrafo $3^{\circ}$ vedou às práticas profissionais de estágio. No entanto, com a portaria do MEC $\mathrm{n}^{\mathrm{o}}$ 544, de 16 de junho de 2020, pelo artigo $3^{\circ}$, foi estabelecido que as práticas de estágio deveriam obedecer às Diretrizes Nacionais Curriculares aprovadas pelo Conselho Nacional de Educação $(\mathrm{CNE})^{5}$, dando uma abertura para que os estágios pudessem acontecer de forma não presencial, em outros termos, no formato remoto. Abertura que foi endossada pelo parecer do CNE n ${ }^{\circ}$ 09/2020 ${ }^{6}$.

Em Minas Gerais, o retorno das aulas na Educação Básica foi iniciado em 18 de maio de 2020 no formato remoto, por meio do Regime Especial de Atividades não Presenciais $(\text { REANP })^{7}$. O REANP foi composto, em 2020, pelas seguintes ferramentas: hotsite Estude em Casa, Planos de Estudos Tutorados (PET), programa Se Liga na Educação e aplicativo Conexão Escola.

Os PET (Figura 1) são apostilas com conteúdos e atividades de cada disciplina a serem executadas e entregues pelos alunos por meio de fotos ou arquivos de diversos modos "1 (WhatsApp, e-mail, entrega na escola). A princípio, ele seria utilizado para contabilizar a frequência dos alunos, mas com a situação de agravamento da pandemia, ao final do ano letivo, foi confeccionado o PET Avaliativo, que consistia em atividades de cada disciplina e uma autoavaliação para atribuição de nota. O programa Se Liga na Educação consiste em aulas transmitidas pela Rede Minas (que podem ser assistidas também pelo Youtube) com base nos PET. As aulas de cada uma das disciplinas ocorrem em um dia específico da semana, tendo 20 minutos de duração para cada etapa de escolaridade, por exemplo, as aulas da disciplina de Matemática ocorrem todas as quartas-feiras. O aplicativo Conexão Escola foi

\footnotetext{
${ }^{4}$ Disponível em: https://www.unifal-mg.edu.br/graduacao/wp-content/uploads/sites/94/2020/06/Resolucao-0162020.pdf. Acesso em 02 jun. 2021.

${ }^{5}$ Disponível em: https://www.in.gov.br/en/web/dou/-/portaria-n-544-de-16-de-junho-de-2020-261924872. Acesso em 02 jun. 2021.

${ }^{6}$ Disponível em: http://portal.mec.gov.br/index.php?option=com docman\&view=download\&alias=147041pcp009-20\&category_slug=junho-2020-pdf\&Itemid=30192. Acesso em 02 jun. 2021.

${ }^{7}$ A regulamentação sobre o REAP está disponível em: https://www2.educacao.mg.gov.br/images/documentos/Resolucao\%20SEE_N_4310.pdf. Acesso em 02 jun. 2020.
} 


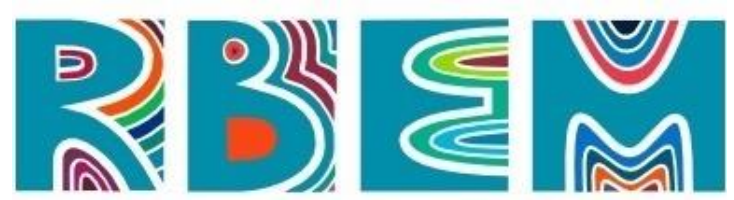

REVISTA BAIANA DE EDUCAÇÃO MATEMÁTICA

uma possibilidade a mais para os alunos terem acesso aos PET e as aulas do programa Se Liga na Educação. Cada escola adotou uma estratégia de acompanhamento dos alunos, usando WhatsApp, Google Meet, Google Classroom, ligações e interações em outras redes sociais.
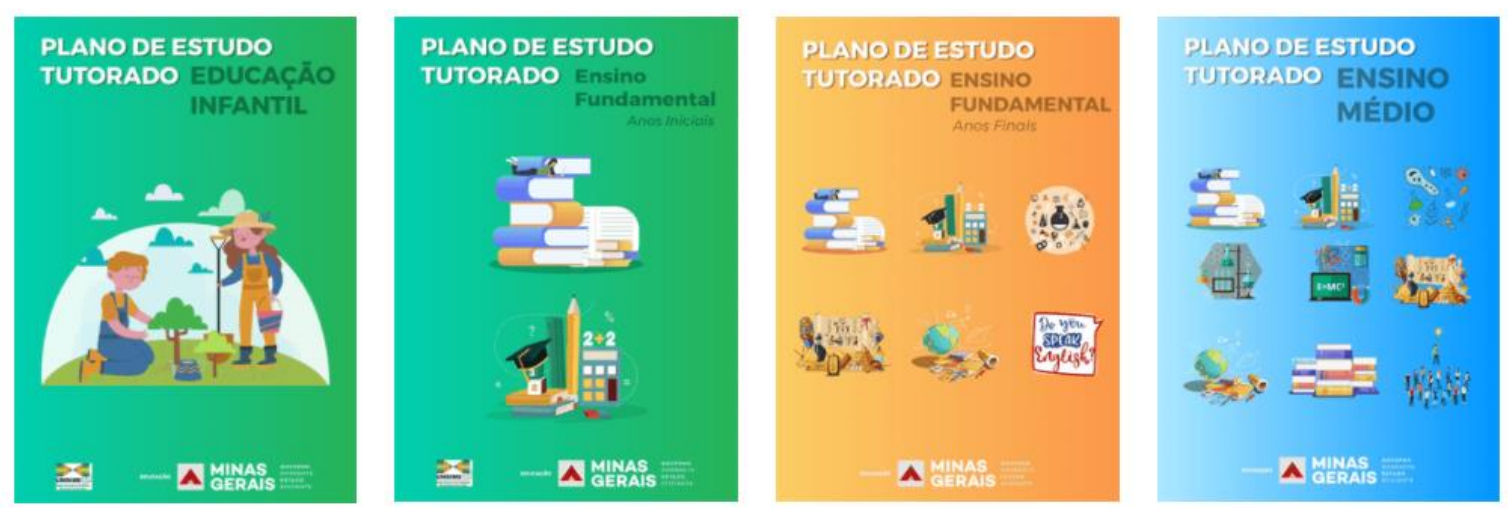

Figura 1: Captura de tela das imagens das capas dos PETS (Disponível em: https://estudeemcasa.educacao.mg.gov.br/inicio. Acesso em 01 jun. 2021).

Com a abertura para a realização do estágio de forma não presencial, pelo MEC e CNE e pela UNIFAL-MG, e com a permissão da Secretaria de Estado de Educação de Minas Gerais (SEE), que solicitou das Instituições de Ensino Superior (IES) um plano de ação para

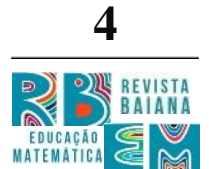
que o estágio pudesse ser realizado no formato remoto, os estágios do curso de MatemáticaLicenciatura da UNIFAL-MG poderiam ser retomados caso os docentes responsáveis (ou professores orientadores) por eles decidissem ofertar as disciplinas ao qual estão vinculados.

Para além das questões operacionais e burocráticas para a realização do estágio no formato não presencial, uma preocupação foi o caráter formativo do estágio. Ele é considerado no regulamento de estágio ${ }^{8}$ do curso de Matemática-Licenciatura da UNIFALMG como um espaço-tempo de aprendizagem através da inserção dos discentes em Instituições de Educação Básica, articulando situações da prática profissional com a formação universitária em um movimento constante de relação entre teoria e prática. A preocupação estava relacionada com o fato de as escolas estarem fechadas para aulas presenciais e, com isso, a inserção dos discentes (ou futuros professores de Matemática) nelas não possibilitariam vivenciar a riqueza do ambiente escolar, tendo uma visão sobre a gestão

\footnotetext{
${ }^{8}$ Disponível em: http://academico.unifal-mg.edu.br/sitecurso/arquivositecurso.php?arquivoId=237). Acesso em 01 jun. 2021.
} 


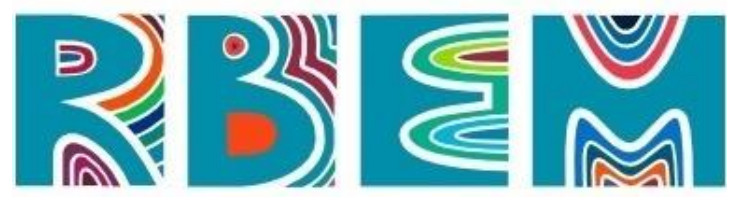

REVISTA BAIANA DE EDUCAÇÃO MATEMÁTICA

escolar, a sala de aula, o contato com professores e alunos e as ações desenvolvidas pela escola.

No entanto, estávamos (e ainda estamos) vivenciando um tipo de escola e educação que poderia (e ainda pode) contribuir para a formação de futuros professores de Matemática pelas práticas profissionais de professores e gestores escolares em um momento histórico singular. Um momento que possibilitaria (e ainda possibilita) modos de produção de significados - entendido como tudo o que uma pessoa pode e efetivamente diz de algo em uma situação (LINS, 1999) - para esse novo formato de educação escolar. Com isso, docentes das disciplinas que contêm os estágios do curso de Matemática-Licenciatura da UNIFAL-MG optaram pela retomada dessas disciplinas e alguns professores da Educação Básica se colocaram disponíveis para acolher os discentes do curso.

A partir disso, os futuros professores de Matemática iniciaram o estágio em uma escola que não conheceram fisicamente, mas que puderam vivenciar as lutas e dilemas de parte de sua comunidade (gestores e professores) neste período de educação em tempos de pandemia e acompanhar as ações da SEE. Algumas dessas vivências serão trazidas para este artigo, na qual nos colocamos na posição de professoras pesquisadoras, tal como discutem Fiorentini e Lorenzato (2009), devido ao estudo intencional e metódico, o que pode implicar em contribuições para a Educação Matemática e ao mesmo tempo para nosso desenvolvimento profissional enquanto parceiras de trabalho, sendo a primeira autora professora formadora/orientadora de estágio na UNIFAL-MG e a segunda autora professora de ensino Médio da SEE, que tem acolhido os estagiários do curso de MatemáticaLicenciatura da UNIFAL-MG, se tornando professora supervisora de estágio.

Dentre as vivências, analisamos neste artigo as discussões sobre as aulas do programa Se Liga na Educação e uma entrevista realizada com a segunda autora, por meio de nossa observação participante. Adotamos como referencial teórico o Modelo dos Campos Semânticos (MCS), produzido por Lins $(1999,2012)$ e teorizações mais específicas sobre estágio. Argumentamos que, de fato, o estágio em tempos de pandemia proporcionou a produção de conhecimentos sobre esse novo tipo de escola e sobre a atividade profissional de professores de Matemática.

\section{Nossas concepções e ações propostas para o estágio no Ensino Médio}




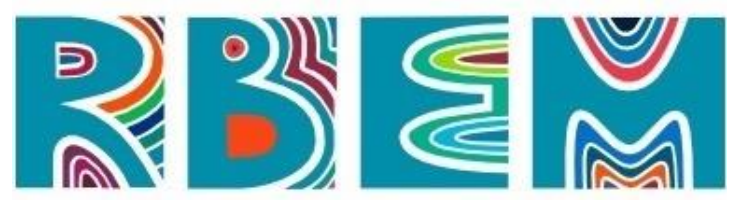

REVISTA BAIANA DE EDUCAÇÃO MATEMÁTICA

O estágio é considerado, como apontam Teixeira e Cyrino (2013) e Silva e Oliveira (2021), como uma etapa central da formação inicial de professores de Matemática pelo contato com seu possível ambiente de trabalho. Apesar disso, os estágios são colocados em posição de inferioridade como componente das licenciaturas em Matemática e há uma quantidade pequena de pesquisas sobre eles na Educação Matemática, de acordo com Silva e Oliveira (2021). Há uma concepção de estágio na qual ele se reduz a observar os professores e imitar modelos considerados eficientes

[...] sem proceder a uma análise crítica fundamentada teoricamente e legitimada na realidade social que o ensino se processa. Assim, a observação se limita à sala de aula, sem análise do contexto escolar, e espera-se do estagiário a elaboração e execução de "aulas-modelo" (PIMENTA; LIMA, p. 29, 2017).

Esta concepção está ancorada, no nosso ponto de vista, em um modo de ver a formação na qual saber muita matemática e modelos considerados como eficientes para ensiná-la assumem centralidade, bastando executar aulas tidas como modelo para que a aprendizagem dos alunos da Educação Básica ocorra. Essas aulas podem estar pautadas em uma visão de ensino que parte do pressuposto que os alunos já são conhecidos/antecipados e basta oferecer um ambiente propício ao seu desenvolvimento, buscando maneiras/metodologias eficientes para que isso aconteça, conforme discutido por Lins (1999).

Lins $(1999,2005)$ fornece outra visão de formação e educação, na qual os professores de Matemática precisam, dentre outras coisas, conhecer metodologias, diferentes teorizações sobre educação e saber mais Matemática, esclarecendo que esse mais não se trata de mais conteúdos "e sim a um entendimento, uma lucidez maior, e isto inclui, necessariamente, a compreensão de que mesmo dentro da Matemática do matemático produzimos significados diferentes para o que parece ser a mesma coisa" (LINS, 2005, p. 122). Nesta outra visão, há a concepção de ensino na qual os alunos não são conhecidos ou antecipados e, por isso, os professores precisam saber quem são e onde estão (que é a realização de leituras deles), para poderem se entender e oferecer a perspectiva de novas aprendizagens, sendo os materiais e as metodologias subordinados a intenção didática dos professores e ao projeto político da escola. Esta visão pode ser combinada com outra vertente que aponta para o desenvolvimento do estágio "como uma atitude investigativa, que envolve a reflexão e a intervenção na vida da escola, dos professores, dos alunos e da sociedade" (PIMENTA; LIMA, 2017, p. 27). Esta 


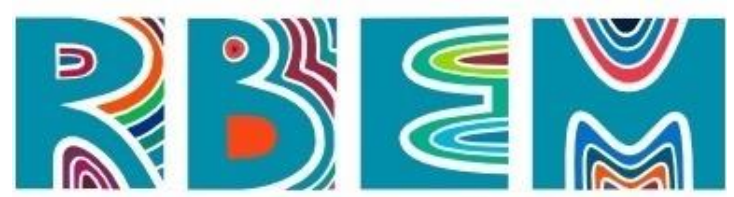

REVISTA BAIANA DE EDUCAÇÃO MATEMÁTICA

perspectiva, segundo Pimenta e Lima (2017) já está presente em práticas de grupos isolados, mas deve ser vista como um horizonte ou utopia a serem alcançados em termos de formação de professores. Ela está relacionada, em nossa leitura, com o entendimento de Pimenta e Lima (2005/2006, p. 6) de que o estágio "se constitui como um campo de conhecimento, o que significa atribuir-lhe um estatuto epistemológico que supera sua tradicional redução à atividade prática instrumental". Nesta direção, podemos produzir conhecimento a partir das situações de estágio, como a realização de leitura da escola, dos alunos e dos seus professores supervisores, que contribuam para a formação de futuros professores de Matemática, assim como de professores formadores (docentes de IES que atuam nas licenciaturas, conforme Coura e Passos (2017)) que realizam as orientações de estágio.

O termo produzir conhecimento, tem sido considerado por nós com base no MCS, em que conhecimento "consiste em uma crença-afirmação (o sujeito enuncia algo em que acredita) junto com uma justificação (aquilo que o sujeito entende como lhe autorizando a dizer o que diz)" (LINS, 2012, p. 12). O conhecimento é algo do domínio da enunciação e, por isso, toda produção de significado implica em produção de conhecimento. Para Lins (1999, p. 89) "não há conhecimento em livros enquanto objetos, pois ali há apenas enunciados. É preciso a enunciação efetiva daqueles enunciados para que eles tomem parte na

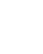
produção de conhecimentos".

Lins (1999) ainda coloca que sempre há um sujeito do conhecimento (e não do conhecer) e que este sujeito "não faz sentido sem o interlocutor em direção ao qual este conhecimento é enunciado" (LINS, 1999, p. 84), um interlocutor que “[...] acredito, diria o que estou dizendo com a justificação que estou produzindo" (LINS, 1999, p. 89). Por isso, "a afirmação de um outro que um conhecimento é melhor, bom ou ruim, assim como decisões sobre se uma enunciação é ou não aceita como legítima por um outro, têm sempre um sujeito, e este sujeito tem intenções" (LINS, 1999, p. 89).

As produções de conhecimento a partir das situações de estágio remoto não são consideradas melhores ou piores, por nós, comparadas a outras situações, são conhecimentos diferentes e os que foram possíveis para o momento, na tentativa de aproximação das práticas profissionais de professores e das vivências escolares.

Cabe dizer que há pouquíssimas pesquisas sobre o estágio na formação de professores de Matemática, com base no MCS. Um exemplo é o trabalho de Julio e Oliveira (2018), que 


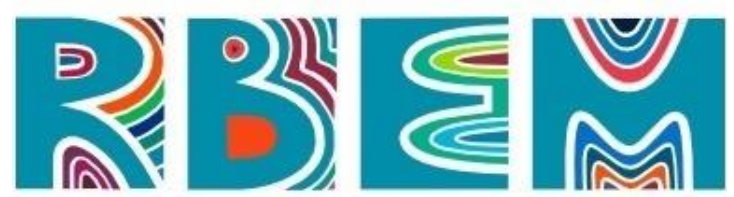

REVISTA BAIANA DE EDUCAÇÃO MATEMÁTICA

fizeram uma diferenciação entre preparar aulas e se preparar para as aulas utilizando o contexto dos estágios, o apontando como um espaço-tempo para exercícios de descentramento e vivências de estranhamentos. Outro exemplo é a pesquisa de Silva (2020) que realizou uma leitura, a partir de entrevistas com futuros professores de Matemática, sobre "ser professor de Matemática". Neste processo, o estágio esteve presente nas falas de seus entrevistados, em que ele foi visto como, por exemplo: relevante para a formação, algo que possibilita um entendimento do que o professor de Matemática deve ou não ser como profissional, uma oportunidade de conhecer a burocracia da escola e não a ser professor (apesar de poder conhecer outras realidades), um lugar para repensar a realidade escolar, insuficiente no quesito de como dar aula de matemática (por considerar que no curso aprende muito mais Matemática do que como ensinar Matemática), um lugar que possibilita contato com a sala de aula.

Neste artigo, estamos focadas nas produções de conhecimentos a partir de situações de estágio no formato remoto. Em todo caso, queremos salientar que ainda há um longo caminho a percorrer em termos de pesquisas envolvendo o estágio na Educação Matemática, como sugerem Silva e Oliveira (2021), e isso não é diferente se tomarmos esta temática a partir dos pressupostos do MCS.

A leitura das produções de significados dos discentes foi feita por meio de observação participante (LUDKE; ANDRÉ, 1986) durante as aulas síncronas da disciplina a qual o estágio está vinculado e dos relatórios produzidos por eles, que permitem o envolvimento das professoras pesquisadoras com a situação, favorecendo totalmente a imersão na realidade explorada .

Essas leituras foram feitas com base no que Lins $(1999,2012)$ chamou de leitura plausível, que "se aplica de modo geral aos processos de produção de conhecimento e significado; ela indica um processo no qual o todo do que eu acredito que foi dito faz sentido. Outra maneira de dizer que faz sentido em seu todo, é dizer que o todo é coerente." (LINS, 2012, p. 23). Nesta leitura não falamos do que o outro disse, mas produzimos significados a partir do que o outro disse (do conhecimento produzido por ele), tentando nos colocar no 


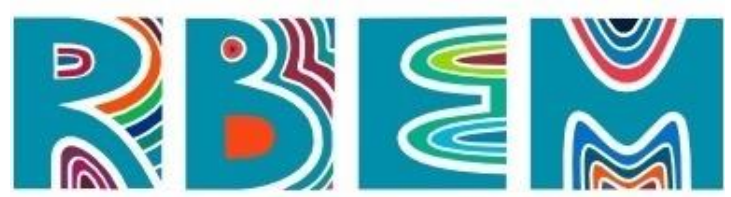

REVISTA BAIANA DE EDUCAÇÃO MATEMÁTICA

lugar dele, fazendo afirmações e nos sentindo autorizadas a fazê-las na direção do que nós acreditamos que tenha sido dito por esse outro ${ }^{9}$.

Tendo em vista nossos posicionamentos sobre o estágio e produção de conhecimento, passamos para a caracterização do estágio no curso de Licenciatura em Matemática e para as ações que foram desenvolvidas assim que o estágio em formato não presencial foi permitido.

O estágio do curso de Matemática-Licenciatura da UNIFAL-MG é caracterizado pelo desenvolvimento de atividades de docência em escolas ou em outros ambientes educativos em consonância com as disciplinas vinculadas a ele (Prática de Ensino e Estágio I, Prática de Ensino e Estágio II, Prática de Ensino e Estágio III, Prática de Ensino e Estágio IV).

A disciplina, a qual o estágio que estamos discutindo estava vinculado, é Prática de Ensino e Estágio III, que ocorreu de 3 de agosto a 09 de novembro de 2020. Ela possui 30 horas teóricas, 30 horas de prática pedagógica e 90 horas de estágio a ser realizado no Ensino Médio (EM). A ementa desta disciplina contempla os seguintes assuntos ${ }^{10}$ : a matemática no EM; ações das políticas públicas educacionais para o EM; elaboração, execução e avaliação de atividades educacionais; estágio no EM.

Os sete discentes matriculados tinham como plano de trabalho de estágio observar e analisar as aulas de Matemática do EM do programa Se Liga na Educação (ministradas pelos professores Flávio Gomes e Alexandre Duarte), analisar os PET do EM, produzir um vídeo educativo sobre conteúdos do EM (que é uma atividade de regência), interagir com a professora supervisora, por meio participação em suas aulas e de uma entrevista, e elaborar um relatório. Tal relatório consistiu na escrita de todas as atividades desenvolvidas na disciplina.

O plano de trabalho foi elaborado pela primeira autora, com base em discussões realizadas com a segunda autora ${ }^{11}$. Por mais que a segunda autora (professora supervisora de estágio) não estivesse interagindo constantemente com os discentes, ela sempre atuou em conjunto com a professora orientadora (primeira autora), trazendo atualizações nas

\footnotetext{
${ }^{9}$ Um histórico e maiores aprofundamentos sobre esse tipo de leitura pode ser visto em Paulo (2020).

${ }^{10}$ Disponível em: http://academico.unifal-mg.edu.br/sitecurso/arquivositecurso.php?arquivoId=239): . Acesso em 02 jun. 2021

${ }^{11}$ É importante dizer que os discentes têm liberdade de escolher as escolas que farão o estágio e, consequentemente os professores supervisores. Eles optaram pela mesma professora supervisora pela parceria que ela tem estabelecido com a professora orientadora e pela disponibilidade/abertura dela em interagir com eles.
} 


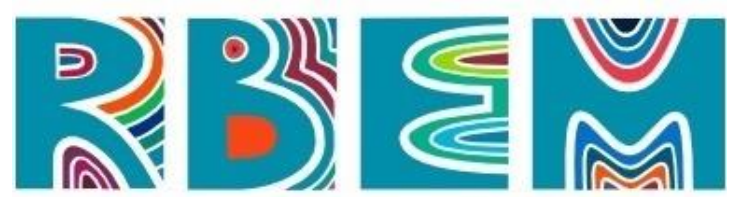

REVISTA BAIANA DE EDUCAÇÃO MATEMÁTICA

orientações da SEE, expondo a situação da escola (gestores, professores e alunos) e comentando sobre sua atuação em duas escolas estaduais de Alfenas (MG).

Para uma análise das produções de conhecimento sobre estágio em formato remoto, vamos direcionar nossa leitura para dois momentos: discussões sobre as observações das aulas de Matemática do programa Se liga na Educação e uma entrevista realizada com a professora supervisora de estágio.

\section{Sobre as observações e análises das aulas}

No aspecto das observações das aulas, um ponto interessante foi o fato de todos os discentes e professora orientadora assistirem as mesmas aulas, diferente do que acontece quando cada discente escolhe diferentes escolas para a realização dos estágios. Por um lado, as discussões realizadas a partir de um mesmo cenário, contribuem para ver os diferentes modos de produção de significados para ele, o que implica em diferentes produções de conhecimento; por outro lado, cenários diferentes, aulas em outras escolas, trazem uma diversidade de situações que ampliam os modos de ver as diferenças entre as escolas e não somente a atuação de professores de Matemática.

A partir de discussões em aulas síncronas com os discentes sobre as aulas de Matemática observadas, do programa Se Liga na Educação, podemos dizer que elas se pautam no método tradicional de ensino, com centralidade no conteúdo Matemático e partindo do pressuposto de um aluno dado, já conhecido de antemão, numa concepção que se assemelha a: "se eu aprendi por este método uma outra pessoa só não aprende se não tiver capacidade, jeito para a coisa" (LINS, 1999, p. 78). Há a possibilidade de inserção de comentários no chat do programa, durante a aula, mas esses comentários não são respondidos em aula. Então, não há foco em interação com os alunos, o que seria complicado também pela quantidade de alunos do estado de Minas Gerais e, até mesmo, de outros estados assistindo essas aulas. Os discentes afirmaram que a metodologia foi a possível para o momento, tendo em vista o alcance pretendido e a situação de urgência em se fazer algo no âmbito educacional, se questionando se seria possível outro modo de dar aula para um grupo grande de pessoas de modo diferente e não chegando a uma resposta. 


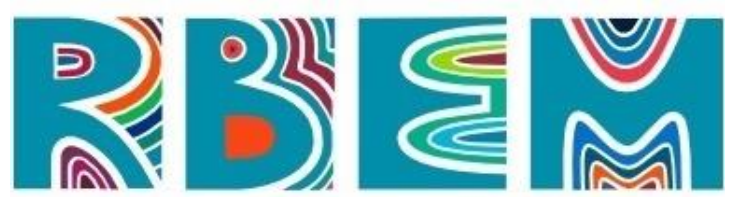

REVISTA BAIANA DE EDUCAÇÃO MATEMÁTICA

Em alguns momentos das aulas síncronas fazíamos comentários mais específicos sobre alguns trechos das aulas de Matemática do EM do programa Se Liga na Educação. Com o relatório parcial de estágio, entregue em setembro de 2020, pudemos notar que cada discente produziu significados distintos para uma mesma aula, como foi o caso da aula com o tema funções do segundo grau ${ }^{12}$. Vamos exemplificar com descrições nossas de três relatos. Em um relato foi mencionado o fato de o professor apresentar gráficos de posições de funções do segundo grau, mas não falar sobre a concavidade delas e foi ressaltado em diversos momentos a segurança e o entusiasmo dele nos momentos da aula e a educação dele com a intérprete de Libras, sempre saudando-a.

O segundo relato focou na linguagem matemática, como o professor falar que o coeficiente $a$ que acompanha o $\mathrm{x}^{2}$ (sendo esta expressão lida como xis dois) em $\mathrm{x}^{2}-3 \mathrm{x}+1=0$ é 1 e não $1 x^{2}$ (lido como um "xis" dois), sendo o termo "xis" dois usado mais vezes durante a aula e foi comentado, também, sobre o exemplo de utilizar a cabeça de um cachorro para exemplificar parábola no dia a dia, sendo que no PET havia exemplos mais interessantes como a Igreja de São Francisco de Assis, projetada por Oscar Niemeyer e localizada no bairro Pampulha, em Belo Horizonte (MG).

E, o terceiro relato focou no modo como o professor fala, também na linguagem matemática, mas trazendo o que isso pode gerar nos alunos. Por exemplo, o professor falou que pode trocar o y for $\mathrm{f}(\mathrm{x})$ tranquilamente e o discente disse acreditar que para os alunos da Educação Básica, que não tiveram contato com esse assunto, ou que não estavam acompanhando a explicação, não entenderiam essa afirmação. O discente ainda mencionou falas errôneas como as de que as funções do segundo grau são parecidas com as funções do círculo e da hipérbole, maneirismos como "joga todo mundo para um lado" ao abordar a resolução de $x^{2}=3 x-1$, usar a expressão xis dois para se referir a $x^{2}$ (o que pode remeter a multiplicação dois vezes x e não a x elevado ao quadrado), falas sem explicações (como mencionar os coeficientes de uma função quadrática e não dizer o que eles são) e escolhas duvidosas de exemplos (como utilizar a cabeça de um cachorro, exemplificado pela Figura 2).

\footnotetext{
${ }^{12}$ Aula disponível em: https://www.youtube.com/watch?v=NRyoOeQLDtI\&list=PLiyVG7yUlUjOs3L2iso3OyZD703MpMAE\&index=55\&t=0s. Acesso em: 02 jun. 2021.
} 

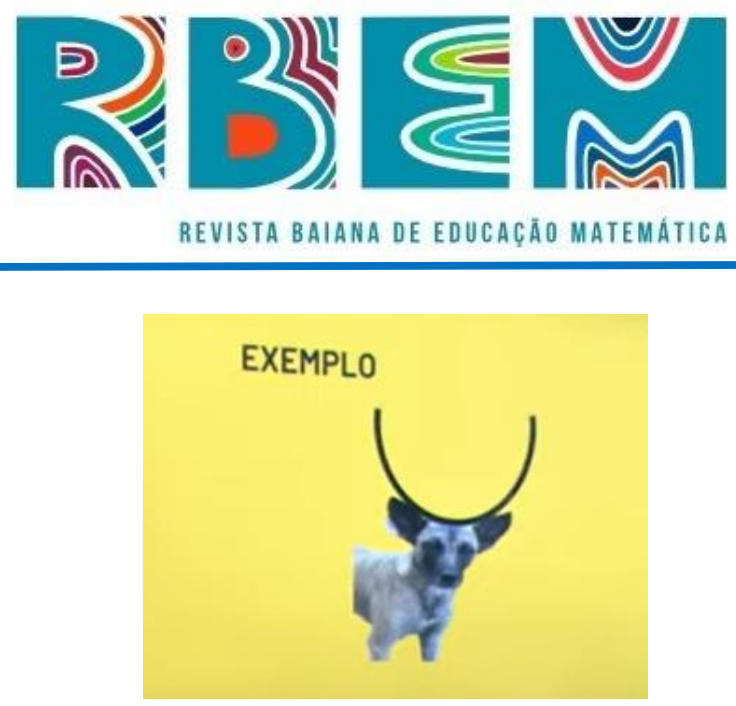

Figura 2. Captura de tela da aula exibida pelo link: https://www.youtube.com/watch?v=NRyoOeQLDtI\&list=PLiyVG7yUlUjOs3L2iso30yZD703MpMAE\&index=55\&t=0s. Acesso em 08 jun. 2021.

A partir dos três relatos mencionados, a primeira autora assistiu novamente a aula sobre função quadrática e aglutinou itens para discussão, conforme o Quadro 1, colocados em forma de frases ou questionamentos. Em uma aula síncrona os três relatos de discentes foram lidos (com a permissão deles e sem identificação dos discentes) e, em seguida, o Quadro 1 foi exposto e cada item foi discutido ${ }^{13}$.

Quadro 1. Pontos para discussão sobre uma aula de funções do segundo grau.

Alguns aspectos da aula:

O professor inicia a aula falando da intérprete, o que valoriza do trabalho dela. Incentiva os alunos a buscarem os professores de suas escolas. Fala pausado, sem correria. Menciona o PET e resolve um exercício dele em aula. Agradece pela atenção no final da aula, pedindo aos alunos que assistam às aulas e busquem tirar dúvidas, dizendo que vai responder para eles, porque quer ajuda-los, envia um abraço e diz fica com Deus. Questão: o que significa estado laico?

Sobre o conteúdo:

a) Fala como: "é simples trocar ( $\mathrm{f}(\mathrm{x})$ por $\mathrm{y})$, não tem que sofrer com isso, ... eu tento mostrar que é algo básico, só troquei, as vezes não me preocupo tanto com os nomes porque quero mostrar que o negócio é tão simples que você bate o olho e já enxerga que é uma função quadrática" pode gerar dificuldade em entender conteúdo e uso constante de termos como simples pode fazer alguém que tem dificuldade se sentir pior.

b) Tem funções parecidas: esfera, círculo, elipse, hipérbole. "Nada é tão idêntica!", "são parecidas mas não são iguais”. Questão: o que significa ser parecida em matemática?, quais as definições dessas "funções parecidas"?

c) "Na função quadrática quem determina o gráfico da função é o valor do coeficiente a". Questão: será mesmo?

d) Traz a equação $x^{2}=3 x-1$ para exemplificar uma função do segundo grau. Questão: ele poderia fazer isso?

e) Uso do termo "jogar todo mundo de um lado para o outro" na equação $x^{2}=3 x-1$ para obter $x^{2}-3 x+1=0$ e comparar $y=x^{2}+b x+c$. Questão: em $x^{2}-3 x+1=0$ temos função?

f) Alertas positivos feitos pelo professor: "o que derruba a gente na resolução dos exercícios

\footnotetext{
${ }^{13}$ Cabe mencionar que as aulas são públicas e, apesar das críticas realizadas, reconhecemos o esforço do professor com as aulas e o quanto a exibição pública deixa as pessoas expostas e vulneráveis a críticas positivas e negativas, um ponto que mereceria uma futura discussão.
} 


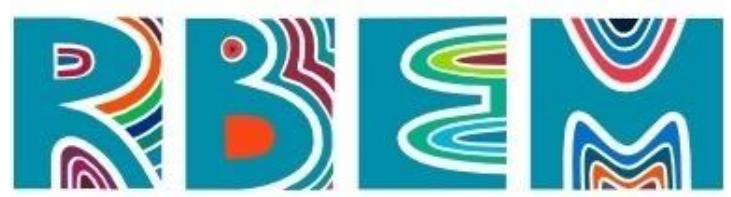

são os sinais, os detalhes".

g) Uso do termo "xis dois" (tempo de vídeo 07:16).

h) Sobre o coeficiente c, foi dito que ele "anda sozinho" e que "Antes só que do mal acompanhado, isso é fato, é verídico na nossa vida, tem situações que é melhor andar sozinho". Comentário: algumas lições para a vida em contexto que pode não ter sido o melhor.

i) Passa para a fórmula de Báskara (tempo de vídeo 08:10). Questão: para que? Alerta: mudança de modos de produção de significados sem avisar os alunos, conforme discute Lins (1999).

j) "delta é chamado de discriminante, vocês vão falar de discriminação, neste caso aqui a gente pode falar em alguns assuntos, [...] para acabar com a discriminação que há em nosso país, ..., tem que parar com isso, nós somos seres humanos, então vamos acabar com a discriminação". Questão: o que acham da comparação de termos matemáticos com outros termos?

k) Tempo de vídeo 09:48, professor utiliza a cabeça de um cachorro (chamada a Katrina) para abordar gráficos, mas traçando somente o eixo x. Questão: foi uma boa relação dia a dia com a Matemática? Foi uma contextualização? Quais possíveis significados para contextualização?

1) Coloca eixo $\mathrm{x}$ e parábola passando em dois pontos e duas situações, utilizando falas como: "a $>0$ (pessoas positivas, fazem um sorriso, já viu essa aula?) e delta>0". "A Katrina está mostrando que deu certo". "parábola voltada para baixo, a $<0$ (pessoas negativas são mais tristes, reclamam mais)". Continua com os casos a $>0$, a $<0$ e análise do delta. Questão: foi uma boa comparação?

m) Não falou do eixo y porque quer que identifique parábola com a função com segundo grau (Tempo de vídeo: 15:56).

n) Traz a Katrina e pergunta se pode traçar o eixo y, respondendo que pode e que ele estará bem no meio do focinho, dizendo que o vértice vai estar centralizado. Questão: Isso pode dar a entender que o y sempre cairá no $\mathrm{x}_{\mathrm{v}}$ ( $\mathrm{x}$ do vértice)?

Fonte: autoras.

Os comentários dos discentes nos impactaram. Assim como eles foram impactados de diferentes modos e produziram diferentes conhecimentos. Ou seja, cada um de nós tivemos diferentes experiências, sendo experiência entendida, de acordo com Larrosa Bondía (BONDÍA, 2002), como tudo aquilo que nos impacta, nos atravessa, nos transforma. Com a leitura dos relatórios parciais dos discentes a primeira autora relatou a eles que as análises deles a ajudou a olhar com mais cuidado para as aulas de Matemática do programa Se Liga na Educação e os discentes disseram ficar impressionados com a aula síncrona e com a diversidade de olhares para uma mesma aula de Matemática e com o fato dela, apesar de ter duração de 20 minutos, poder possibilitar tanta discussão, ampliando os olhares de cada um para análise de aulas de Matemática.

Apesar dessa ampliação de olhares para as aulas, os discentes relataram cansaço de assistir 30 horas de aulas, que foram solicitadas a eles no plano de trabalho, pelo estilo repetitivo de aula e por faltar a diversidade de outras situações (como interação entre alunos e 


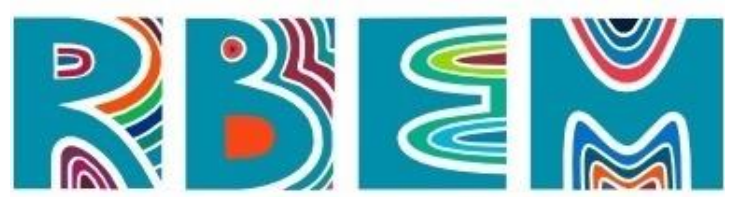

REVISTA BAIANA DE EDUCAÇÃO MATEMÁTICA

entre alunos e professores). E, disseram, ainda, sentir falta de contato presencial com as pessoas da escola, principalmente com os alunos.

\section{Situação docente a partir de uma entrevista}

Uma das atividades de estágio consistia em interação com a professora supervisora de estágio. Ela esteve presente de forma constante com a professora orientadora de estágio, em algumas aulas síncronas com os discentes e em um momento de entrevista, na qual um roteiro semiestruturado foi elaborado colaborativamente pela professora orientadora e pelos discentes. O roteiro semiestruturado continha as seguintes perguntas, expostas no Quadro 2.

Quadro 2. Roteiro de entrevista elaborado coletivamente.

Roteiro para entrevista com professora preceptora:

1- Como foi para você a mudança repentina do ensino presencial para o remoto? Vocês tiveram acesso a um curso de formação para lidar melhor com essa nova modalidade? E em questão de equipamentos, já os tinha ou foi necessário adquirir por conta própria para atender melhor os alunos?;

2 - Em algum momento da sua carreira acadêmica já tinha sido preparada para uma situação de ensino/aprendizagem como essa a qual vivenciamos?;

3 - Como seus alunos estão desenvolvendo nesse período? Alunos que tinham responsabilidade na disciplina ainda continuam na mesma responsabilidade nesse ensino remoto?;

4 - Sabe nos contar como estão psicologicamente seus alunos? Algum relato dos seus alunos que te deixou abalada ou motivada?;

5 - Como e quais recursos tem utilizado para avaliar a aprendizagem dos seus alunos durante as atividades remotas?;

6 - Durante as atividades remotas, você considera que o trabalho docente aumentou? E se aumentou, essa situação causa qual impacto na sua produtividade e qualidade de vida?;

7 - Os alunos têm os PET como material base, e devem assistir as aulas do "Se Liga na Educação". Como é para você orientar seus alunos, uma vez que eles também têm os professores do programa como orientadores?;

8 - Como os docentes da escola com qual você é envolvida pensam sobre a eficácia do ensino de Matemática em tempos de pandemia?;

9 - Logo no que seria o cabeçalho do PET de cada ano do Ensino Médio, são informadas as 


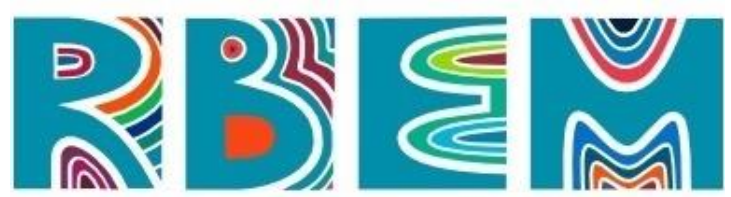

REVISTA BAIANA DE EDUCAÇĀO MATEMÁTICA

quantidades de aulas semanais e mensais. Entretanto para todos os anos, é informado que se tem 4 aulas semanais e 16 mensais, contudo, o primeiro e segundo ano têm 1 aula semanal e portanto 4 mensais, e o terceiro ano 2 semanais e 8 mensais. Gostaria de saber se você já tinha notado tal fato, e se a contagem é desta forma como mencionei, ou se há contagem de aula fora das que são disponibilizadas no YouTube, como aulas de dúvidas por exemplo;

10 - O que você acha da parte destinada a matemática no PET (Plano de Estudo Tutorado)? Acha bom o suficiente para dar apoio aos alunos durante as aulas remotas?;

11 - Acredita que os conteúdos presentes no PET são fiéis ao que seria ensinado se estivéssemos tendo aulas presenciais?;

12 - Você também assiste as aulas do Estado? O que acha da postura dos professores durante as aulas?;

13 - Com a possível volta do ensino presencial, a escola já pensou em como lidar com o aluno que não participou ativamente das atividades propostas para no ensino remoto? E com o aluno que apesar da participação não consolidou bem os conteúdos trabalhados, pretende retomá-los?;

14 - O governo de Minas anunciou a retomada das aulas presenciais em outubro. Já houve alguma discussão sobre isso na escola? O que pensa sobre isso?

Fonte: autoras.

Vamos fazer um comentário geral da entrevista, aglutinando algumas respostas a partir do que os discentes abordaram em seus relatórios finais de estágio.

A professora relatou que "Foi um começo muito assustador, pois quando as aulas foram suspensas se falava em ensino à distância, mas não sabíamos como seria, me sentia no escuro e desesperada, afinal sem saber como ajudar os alunos" (trecho de entrevista com a professora supervisora). Com a retomada não presencial do ensino em 2020, por meio do REANP, não houve um curso de formação para lidar com o que a SEE estava propondo e houve dificuldades de conversar com os alunos pelo aplicativo Conexão Escola, pela não adaptação deles, o que levou a necessidade de criação de grupos do WhatsApp, que os alunos são mais familiarizados, salas no Google Classroom, encontros pelo Google Meet e utilização de e-mail para organizar o contato com os alunos. Sobre este início do REANP, ela ainda falou: "No início fiquei confusa quanto a essa orientação. A maioria dos alunos não entraram em contato para tirar dúvidas, mas sim para tirar dúvidas operacionais" (trecho de entrevista com a professora supervisora). Isso continuou acontecendo no decorrer de 2020. 


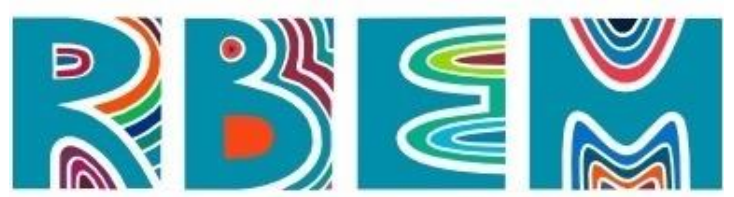

REVISTA BAIANA DE EDUCAÇÃO MATEMÁTICA

Com todas essas ferramentas, a participação dos alunos não acontecia, na maioria das vezes, sendo apontada, com base em conversas da segunda autora com eles, a falta de acesso, a necessidade de trabalhar e de ajudar em casa, expectativa do retorno presencial e dificuldade de adaptação com o novo formato. Uma hipótese levantada pela professora supervisora para a não participação deles é a possibilidade de entrega dos PET no final do ano, podendo fazer com que alguns deixem para última hora. Foi dito que nem sempre os melhores alunos do ensino presencial, são os melhores no ensino remoto, exemplificando com um aluno que era tímido e começou a entrar mais em contato. Mas, no geral, os alunos, estão sentindo falta da escola e dos professores, ansiosos, abandonados e carentes. E, sobre as aulas, a professora supervisora disse que os alunos com os quais ela tem interagido, estão assistindo mais aulas no Youtube do que as aulas do programa Se liga na Educação.

A professora supervisora ainda disse que os sentimentos relatados sobre os alunos também têm sido dos professores, seus colegas de trabalho. Uma homenagem recebida de uma aluna motivou os professores da escola a continuarem perseverantes. Ela disse que a carga horária de trabalho aumentou porque antes tinha horário certo e agora, no ensino remoto, precisa estar mais disponível para os alunos para tentar não perder a participação deles (quando ocorre), o que prejudica na privacidade, pois recebe mensagens até de madrugada.

Sobre as entregas do PET, a professora relatou que o papel dos professores foi apenas de corrigir os exercícios e contabilizar a carga horária, não podendo, a princípio atribuir uma nota para as atividades realizadas. Uma dificuldade encontrada no recebimento dos PET foi a entrega deles sem identificação e com fotos sem nitidez, dificultando o trabalho de corrigir e de contabilizar a carga horária dos alunos. Além disso, ela tem atuado mais tirando mais dúvidas operacionais, como já comentado, e no preenchimento de formulário individual e semanal de cada aluno.

A professora não precisou comprar nenhum dispositivo para o ensino remoto, mas disse que tem colegas de trabalho que precisaram trocar o celular ou adquirir um notebook para atuar no ensino remoto. Além disso, houve dificuldade de alguns professores da escola com a utilização de ferramentas digitais de ensino.

Em relação às aulas e aos PET, a professora achou o material bom devido ao tempo que tiveram para prepará-los, mas a aula muito curta. Para ela, a aula deveria ser, no mínimo 


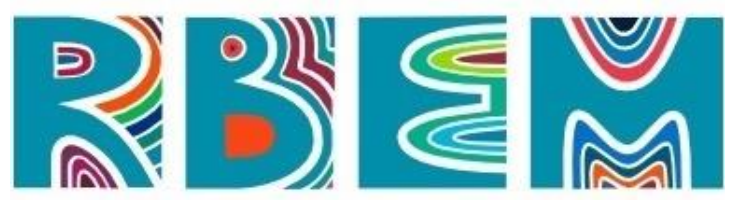

REVISTA BAIANA DE EDUCAÇÃO MATEMÁTICA

de 30 minutos, por ter muito conteúdo. Em relação à performance dos professores de Matemática do programa Se Liga na Educação, ela preferiu não comentar.

Quanto ao pronunciamento do governador de MG de um retorno presencial em outubro de $2020^{14}$, a professora afirmou que "A informação nos pegou de surpresa, foi uma bomba; nós tivemos reunião ontem [28/09/2020], e os diretores não deram o veredito, pois ainda está sendo realizada uma análise sanitária dos municípios" (trecho de entrevista com a professora supervisora). Mas, de acordo com ela, a decisão seria opcional por parte dos alunos e o retorno gradativo, começando pelo $3^{\circ}$ ano do Ensino Médio, e que o ensino remoto continuaria mesmo que ocorresse esse retorno gradativo.

A partir desses relatos, o que ficou para nós autoras e para os discentes foi o esvaziamento das "salas de aulas", algo constatado pela segunda autora, devido sua atuação profissional e contato com outros colegas de trabalho e acompanhado pelos discentes quando participaram dos horários de encontro da segunda autora com os alunos pelo Google Meet e nenhum aluno aparecia. O esvaziamento foi acompanhado por uma luta constante dos professores da escola para interagir com os alunos, seja por WhatsApp, pelo Google Meet, por e-mail ou por ligações, recebendo mensagens a qualquer hora do dia para que nenhum aluno ficasse sem resposta e pudesse prosseguir nos estudos.

Quanto ao fazer docente, ficou claro, pela entrevista, que uma política de governo, como o REANP, acabou deixando a participação dos professores em segundo plano, sem qualquer flexibilidade curricular, sem autonomia e como administradores/gestores de um processo, por corrigir exercícios, preencher formulários e retirar dúvidas de alunos. Com isso, não estamos afirmando que o professor deva ser o centro do processo educacional, mas, inspiradas em Lins (1999), consideramos que ele é figura central para a leitura dos alunos e para a proposição de projetos interessantes e relevantes que levem em conta essa leitura, sua intenção didática e a proposta escolar.

Com a entrevista, pudemos conhecer a prática profissional da segunda autora, que atua em duas escolas estaduais e, com ela, um pouco da realidade escolar e das situações de outros

\footnotetext{
${ }^{14}$ Disponível em: https://www1.folha.uol.com.br/cotidiano/2020/09/governo-de-mg-anuncia-retorno-gradual-aaulas-presenciais-em-

outubro.shtml\#: :text=Sem\%20apresentar\%20protocolos\%20de\%20sa\%C3\%BAde,do\%20dia\%205\%20de\%20 outubro.\&text $=$ Segundo $\% 20 \mathrm{o} \% 20$ governo $\% 2 \mathrm{C} \% 20 \mathrm{a} \% 20$ data,retomada $\% 20$ imediata $\% 20$ das $\% 20$ aulas $\% 20$ prese nciais. Acesso em 07 jun. 2021.
} 


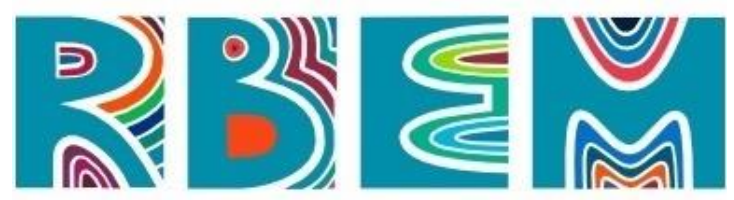

REVISTA BAIANA DE EDUCAÇÃO MATEMÁTICA

professores, produzindo significados para a prática docente em um momento singular na educação em Minas Gerais.

\section{Considerações finais}

Neste artigo relatamos o processo de interrupção do ensino presencial no Brasil e o percurso percorrido para que o estágio supervisionado de futuros professores de Matemática do curso de Matemática-Licenciatura da UNIFAL-MG pudesse ser realizado no formato remoto. Enquanto a professora orientadora acreditava que se havia algum processo educacional ocorrendo em Minas Gerais, então os discentes poderiam participar deles enquanto estagiários e se aproximar da prática profissional, a professora supervisora acreditava que teria condições de oferecer suporte no aspecto do acompanhamento. Isso só foi possível com a crença comum, da importância do estágio na formação de futuros professores de Matemática. Enquanto pesquisadoras, consideramos, baseadas em Pimenta e Lima (2005/2006), que o estágio possui um estatuto epistemológico, ou seja, permite produções de significado (LINS, 1999), que implicam em produções de conhecimentos, a partir de vivências na escola que passamos a ter durante a pandemia.

Por meio das observações das aulas de Matemática do Ensino Médio, através do programa Se Liga na Educação, as professoras e os discentes puderam analisar as aulas de Matemática de dois professores e fazer discussões sobre o aspecto metodológico, a abordagem do conteúdo matemático e a performance deles diante das câmeras, produzindo diferentes significados que ampliaram nosso modo de observar e analisar as aulas. E, por meio de uma entrevista com a segunda autora, os discentes puderam interagir mais com ela e conhecer como tem a sido a prática profissional de professores durante o REANP, implementado pelo governo de Minas Gerais, em 2020.

Baseadas nas teorizações trazidas para este artigo e nos modos como futuros professores de Matemática falaram sobre o estágio na pesquisa de Silva (2020), acreditamos que o estágio remoto, ainda que tenha prejudicado a riqueza de vivências que poderiam ocorrer presencialmente em uma escola, como as interações que ocorrem em sala de aula, possibilitou produções de conhecimento a partir das ações realizadas neste período de pandemia. E, tendo em vista que se tratava de discentes no penúltimo período do curso de 


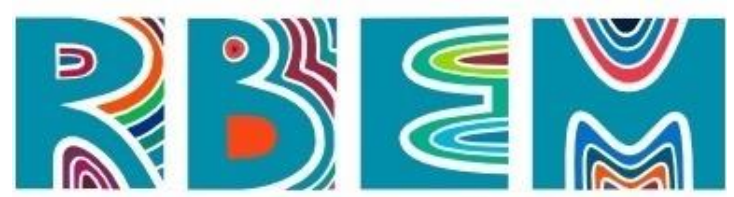

REVISTA BAIANA DE EDUCAÇÃO MATEMÁTICA

Matemática-Licenciatura da UNIFAL-MG e que a sala de aula pode ser uma opção de atuação profissional em breve, as vivências de estágio puderam aproximá-los de uma realidade que poderão enfrentar enquanto professores iniciantes.

Por fim, queremos dizer que o MCS se constitui como um referencial teórico que pode subsidiar novas pesquisas sobre o estágio nos cursos de formação inicial de professores de Matemática como, por exemplo, as atividades de regência de futuros professores de Matemática em tempos de pandemia, e que houve mudanças na política educacional implementada pela SEE para o ano letivo de 2021, que também está acontecendo em formato remoto, mas elas ainda estão em análise por nós.

\section{Agradecimentos}

Agradecemos aos sete discentes da disciplina de Prática de Ensino e Estágio III que puderam compartilhar conosco seus modos de produção de significados e nos ajudar a melhorar nossa prática docente, em especial aos discentes Amanda de Melo Souza e Thales Rangel Ferreira, que leram e comentaram sobre a legitimidade das discussões relatadas neste artigo.

\section{Referências}

BONDIA, J. L. Notas sobre a experiência e o saber de experiência. Revista Brasileira de Educação, n. 19, p. 20-28, Jan./Fev./Mar./Abr., 2002. Disponível em: https://www.scielo.br/j/rbedu/a/Ycc5QDzZKcYVspCNspZVDxC/?lang=pt\&format=pdf. Acesso em: 16 jun. 2021.

COURA, F. C. F.; PASSOS, C. L. B. Estado do conhecimento sobre o formador de professores de Matemática no Brasil. Zetetiké, Campinas, v. 25, n. 1, p. 7-26, 2017. Disponívem em: https://periodicos.sbu.unicamp.br/ojs/index.php/zetetike/article/view/8647556/15716. Acesso em: 16 jun. 2021.

FIORENTINI, D.; LORENZATO, S. Investigação em educação matemática: percursos teóricos e metodológicos. 3 ed. Campinas, SP: Autores Associados, 2009.

JULIO, R. S.; OLIVEIRA, V. C. A. de. Estranhamento e descentramento na prática de formação de professores de Matemática. Boletim GEPEM, n.72, 112-123, 2019. Disponível 


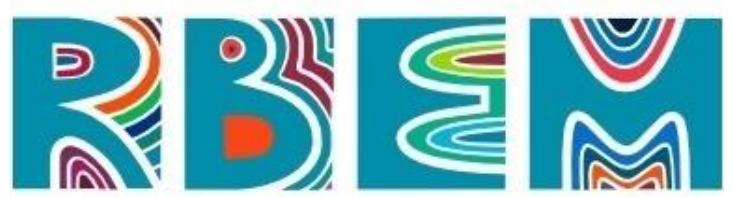

REVISTA BAIANA DE EDUCAÇÃO MATEMÁTICA

em: http://dx.doi.org/10.4322/gepem.2018.008. Acesso em: 13 set. 2021.

LINS, R. C. Por que discutir teoria do conhecimento é relevante para a Educação Matemática. In: BICUDO, M. A. V. (org.). Perspectivas em educação matemática: concepções e perspectivas. São Paulo: Editora da Unesp, 1999, pp. 75-94.

LINS, R. C. O modelo dos campos semânticos: estabelecimento e notas de teorizações. In: ANGELO, C. L. et al. (Org.). Modelo dos Campos Semânticos e Educação Matemática: 20 anos de história. São Paulo: Midiograf, 2012. p. 11-30.

LUDKE, M.; ANDRÉ, M. E. D. A. A pesquisa em Educação: abordagens qualitativas. São Paulo: EPU, 1986.

PAULO, J. P. A. Compreendendo formação de professores no âmbito do Modelo dos Campos Semânticos. 2020. 294p. Tese (Doutorado em Educação Matemática) - Instituto de Geociências e Ciências Exatas, Universidade Estadual Paulista, Rio Claro, 2020. Disponível em: https://repositorio.unesp.br/handle/11449/191665. Acesso em: 16 jun. 2021.

PIMENTA, S. G.; LIMA, M. S. L. Estágio e docência: diferentes concepções. Revista Poíesis, v. 3, n. 3 e 4, p. 5-24, 2005/2006. Disponível em: https://www.revistas.ufg.br/poiesis/article/view/10542/7012. Acesso em: 16 jun. 2021.

PIMENTA, Selma Garrido; LIMA, Maria Socorro Lucena. Estágio e Docência. 8 ed. São Paulo: Cortez, 2017.

SILVA, W. L. M. Uma leitura de falas de licenciandos em Matemática sobre "ser professor de Matemática”. 2020. 184 f. Dissertação (Mestrado em Educação) - Universidade Federal de Alfenas, Alfenas, MG 2020. Disponível em: https://bdtd.unifalmg.edu.br:8443/handle/tede/1687. Acesso em: 13 set. 2021.

SILVA, U. D. DA; OLIVEIRA, A. T. C. C. DE. Influências do Estágio Supervisionado para Professores de Matemática em Início de Carreira - buscando compreender escolhas e características das escolas-campo. Revista Baiana de Educação Matemática, v. 2, n. 01, jan. 2021. Disponível em: https://doi.org/10.47207/rbem.v2i01.10252. Acesso em: 12 set. 2021.

TEIXEIRA, B. R.; CYRINO, M. C. C. T. O estágio supervisionado em cursos de licenciatura em Matemática: um panorama de pesquisas brasileiras. Educação Matemática Pesquisa, São Paulo, v.15, n.1, pp.29-49, 2013. Disponível em: https://revistas.pucsp.br/index.php/emp/article/view/13048/pdf. Acesso em: 12 set. 2021.

Artigo submetido em: 16/06/2021

Artigo aceito em: 20/09/2021 